\title{
Influence of ferroelectric dipole on the photocatalytic activity of
}

\author{
$\mathrm{BaTiO}_{3} / \alpha-\mathrm{Fe}_{2} \mathrm{O}_{3}$ \\ Yongfei Cui, Joe Briscoe, Rory Wilson, Nadezda V. Tarakina, Steve Dunn* \\ Materials Research Institute, School of Engineering and Materials Science \\ Queen Mary University of London
}

\begin{abstract}
Using $\mathrm{BaTiO}_{3}$ as a model ferroelectric material we investigated the influence of the ferroelectric dipole on the photocatalytic activity of a heterogeneous $\mathrm{BaTiO}_{3} / \alpha-\mathrm{Fe}_{2} \mathrm{O}_{3}$ photocatalyst in the decolourisation of Rhodamine B under AM 1.5 G illumination. Two distinct $\mathrm{BaTiO}_{3}$ samples were used: one with a lower ferroelectric content (BTO) and the other a higher ferroelectric content (BTO-A). It was found that under the identical experimental conditions, the half-time of photodecolourisation $\left(t_{1 / 2}\right)$ was reduced from 87 min for $\mathrm{BTO} / \alpha-\mathrm{Fe}_{2} \mathrm{O}_{3}$ to $55 \mathrm{~min}$ for $\mathrm{BTO}-\mathrm{A} / \alpha-\mathrm{Fe}_{2} \mathrm{O}_{3}$. The reduction of half-time demonstrated a significant improvement of photocatalytic activity of $\mathrm{BTO}-\mathrm{A} / \alpha-\mathrm{Fe}_{2} \mathrm{O}_{3}$ when compared to $\mathrm{BTO} / \alpha-\mathrm{Fe}_{2} \mathrm{O}_{3}$. Considering the similar surface areas and morphologies of the two catalysts, we propose that the enhanced decolourisation rate of the dye is due to the improved charge carrier separation and extended charge carrier lifetime arising from an interaction with the ferroelectric dipole and the carriers in hematite. Our results demonstrate a new process to control carrier recombination and use the ferroelectric dipole to control the charge carrier transport, overcome their recombination, and extend the charge carrier lifetime of the surface material in a heterogeneous catalyst system.
\end{abstract}

\section{Introduction}


Heterojunctions between semiconductor photocatalysts have been regarded as an effective strategy to improve the overall photocatalytic efficiency through manipulation the interfacial charge transport[1,2], enhancement of visible-light-harvesting[3,4], etc. Ferroelectric materials with a built-in electric field, or piezoelectric materials that develop a polarisation when undergoing strain have been demonstrated to be promising candidates for photocatalysts[5,6] and other optoelectronic[7], energy harvesting[8,9] and electronic devices[10], where aspects of device architecture and materials structures[11,12] influences the performance of a device. The spontaneous polarisation and the associated depolarisation field in ferroelectric materials can drive spatial separation of charge carriers, which will further result in spatially separated redox reactions happening on the surface $[13,14]$.

This raises the question of whether these systems can be combined such that the ferroelectric dipoles in ferroelectric materials affect the adjacent nonferroelectric material in a heterojunction. It has been reported that the water decomposition rate on the thin layer of $\mathrm{TiO}_{2}$ deposited on ferroelectric $\mathrm{LiNbO}_{3}$ was polarisation-dependent[15]. This was attributed to the charge carrier behaviours of $\mathrm{TiO}_{2}$ being affected by the underlying ferroelectric dipole. In addition, it has been found that the redox reactions taking place on a thin layer of nonferroelectric $\mathrm{TiO}_{2}$ were spatially separated due to influence from the ferroelectric $\mathrm{BaTiO}_{3}$ substrate[16,17]. The reason was considered to be that the spatially separated charge carriers generated in the substrate were able to tunnel through the $\mathrm{TiO}_{2}$ layer and take part in the photochemical reactions. All of these reports suggest the promise of combining ferroelectric materials with non-ferroelectric materials, especially when the anomalous band positions[18] and extended carrier lifetime of a non-centrosymmetric material are considered[19].

In this work, we chose $\mathrm{BaTiO}_{3}$ as the subject of our investigation, which has been previously shown to show interesting properties when used in photocatalysis[6,20]. Hematite $\left(\alpha-\mathrm{Fe}_{2} \mathrm{O}_{3}\right)$ was chosen as the nonferroelectric material, which has been widely applied in 
photocatalysis[21] but with the disadvantages of a very short hole diffusion length and charge carrier lifetime[22]. $\mathrm{BaTiO}_{3}$ and $\alpha-\mathrm{Fe}_{2} \mathrm{O}_{3}$ were combined to form heterostructured photocatalysts and the influence of the ferroelectric dipole was investigated.

\section{Experimental Methods}

The as-received $\mathrm{BaTiO}_{3}(99.9 \%$ trace metal basis, $<2 \mu \mathrm{m})$ was purchased from Sigma. A simple thermal treatment $\left(1200^{\circ} \mathrm{C}\right.$ for 10 hours in air) was adapted to increase the ferroelectric tetragonal phase content, following the reported method [6]. The as-received and annealed samples were named as BTO and BTO-A.

The heterostructured catalysts $\mathrm{BaTiO}_{3} / \alpha-\mathrm{Fe}_{2} \mathrm{O}_{3}$ were synthesized by deposition of $\mathrm{Fe}^{3+}$ on the surface, followed by annealing [23,24]. Specifically, 1.5 g BTO or BTO-A was loaded into $30 \mathrm{ml}$ ethanol solution with a $\mathrm{Fe}^{3+}$ concentration of $0.01 \mathrm{M} \mathrm{Fe}\left(\mathrm{NO}_{3}\right)_{3} \cdot 9 \mathrm{H}_{2} \mathrm{O}$. After stirring and ultra-sonication for 30 mins each, the solution was evaporated at $50{ }^{\circ} \mathrm{C}$. Then the resultant powder was annealed at $300{ }^{\circ} \mathrm{C}$ for 10 minutes, followed by ethanol washing thoroughly. Finally the powder was annealed at $300{ }^{\circ} \mathrm{C}$ for 6 hours. The synthesized samples were named $\mathrm{BTO} / \mathrm{Fe}_{2} \mathrm{O}_{3}$ and $\mathrm{BTO}-\mathrm{A} / \mathrm{Fe}_{2} \mathrm{O}_{3}$.

Powder X-ray diffractograms were collected on a Panalytical X'Pert Pro diffractometer (Panalytical, Almelo, Netherlands) with an $\mathrm{X}^{\prime}$ Celerator RTMS detector using $\mathrm{Cu}-\mathrm{K} \alpha$ radiation and $1 / 4^{\circ}$ divergence slits. Data were collected from $5^{\circ}$ to $120^{\circ}$ with intervals of $\Delta 2 \theta=0.0167^{\circ}$ and a counting time at each point of 200 seconds equivalent. The samples were mounted on zero background silicon substrates.

The microstructures and composition of powder samples were studied by scanning electron microscope (SEM, FEI Inspect F) and transmission electron microscope (TEM, Jeol JEM 2010). In addition, the surface compositions of photocatalysts were investigated as well by Xray photoelectron spectroscopy. The BET surface area of powder photocatalysts were 
analysed using Micromeritics Gemini VII surface area analyzer using $\mathrm{N}_{2}$ as the adsorptive gas. Before the measurement, the samples were dehydrated at $100^{\circ} \mathrm{C}$ for 4 hours under $\mathrm{N}_{2}$ atmosphere. The optical properties of photocatalysts were measured on Perkin Elmer Lambda $950 \mathrm{UV}$-Vis spectrophotometer with an integrated sphere attachment by converting the diffuse reflectance spectrum.

The photocatalytic activity of the catalysts was evaluated by decolourisation of Rhodamine B (RhB, Sigma, $99.99 \%$ ) dye solution under artificial solar light (Newport, class ABB) fitted with an AM 1.5 filter. $0.15 \mathrm{~g}$ catalyst powder was mixed with $50 \mathrm{ml}$ of $10 \mathrm{ppm}$ dye solution, followed by stirring in the dark for 30 minutes before exposure under irradiation with an intensity of 1 sun $\left(100 \mathrm{mWcm}^{-2}\right)$. Equal amounts of solutions were taken for sampling every 30 minutes. After centrifugation to remove the powder catalysts, the optical absorption intensity of the clear solutions was measured using a Perkin Elmer Lambda 950 UV-Vis spectrophotometer.

\section{Results and Discussion}

\section{Characterisation of photocatalysts}

The phase compositions of heterogeneous photocatalysts were analysed by XRD, as shown in Fig. 1. The diffraction peaks can be indexed to cubic or tetragonal $\mathrm{BaTiO}_{3}$, and no characteristic peaks of $\alpha-\mathrm{Fe}_{2} \mathrm{O}_{3}$ are observed. This can be explained by the low loading $(\sim 0.16$ wt $\%$ ) and nanocrystallinity (see Fig. 4.(c) and (d)) of $\alpha-\mathrm{Fe}_{2} \mathrm{O}_{3}$ on the surface.

The X-ray data were modelled by Rietveld refinement using the program GSAS [25]. The relative weight fractions of the cubic and tetragonal phases, in both the BTO and BTO-A samples, along with their unit cell parameters and a relative estimate of their particle sizes and strains were obtained (Tab. 1). These showed that the BTO-A sample contained more of the tetragonal phase. This variation of the ferroelectric phase content, in these samples, may 
provide a possible way to investigate the influence of the ferroelectric dipole on the photocatalytic activity of heterostructured photocatalysts.

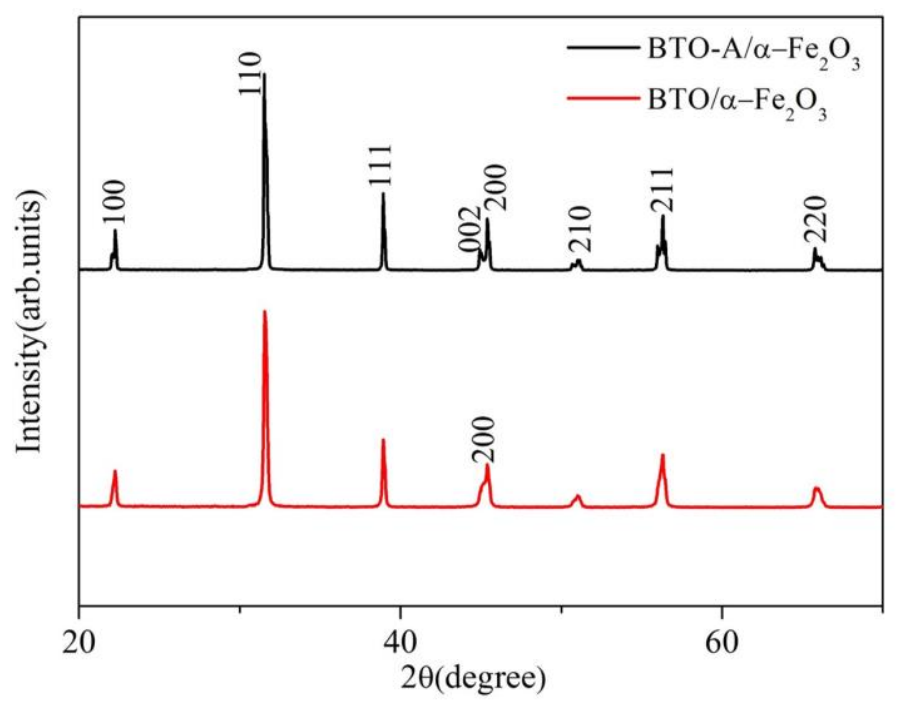

Figure 1. XRD patterns of BTO/ $\alpha-\mathrm{Fe}_{2} \mathrm{O}_{3}$ (bottom) and BTO-A/ $\alpha-\mathrm{Fe}_{2} \mathrm{O}_{3}$ (top). The more distinct splitting of peaks at $45^{\circ}$ shows more tetragonal phases in the post anneal samples. No characteristic peaks for $\alpha-\mathrm{Fe}_{2} \mathrm{O}_{3}$ are observed.
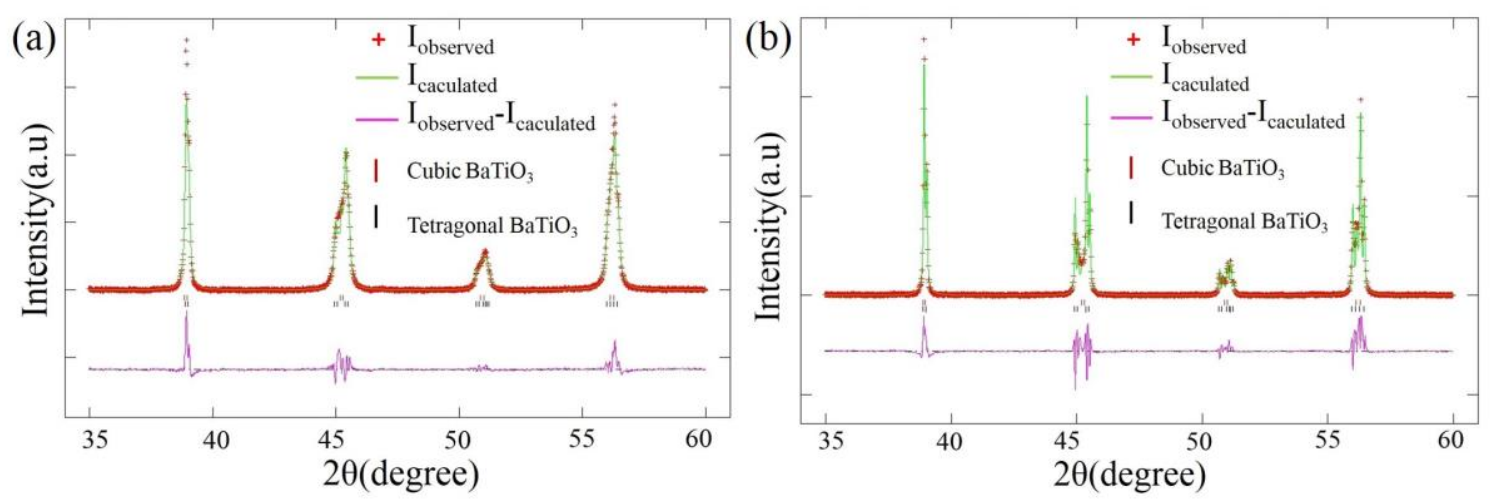

Figure 2. Detail of XRD patterns of (a) BTO and (b) BTO-A showing the fit of the Rietveld refinement.

Note: Full XRD patterns are given in supplementary section. 
Table 1 Crystallographic data of rietveld refinement for BTO and BTO-A

\begin{tabular}{|c|c|c|c|c|c|c|c|c|}
\hline Sample & \multicolumn{4}{|c|}{ BTO } & \multicolumn{4}{|c|}{ BTO-A } \\
\hline $\mathrm{R}_{\mathrm{wp}}$ & \multicolumn{4}{|c|}{0.1364} & \multicolumn{4}{|c|}{0.2373} \\
\hline $\begin{array}{l}\text { Reduced } \chi^{2} \text { or } \\
\text { GoF }\end{array}$ & \multicolumn{4}{|c|}{2.853} & \multicolumn{4}{|c|}{7.467} \\
\hline Compounds & \multicolumn{2}{|c|}{$\mathrm{BaTiO}_{3}$} & \multicolumn{2}{|c|}{$\mathrm{BaTiO}_{3}$} & \multicolumn{2}{|c|}{$\mathrm{BaTiO}_{3}$} & \multicolumn{2}{|c|}{$\mathrm{BaTiO}_{3}$} \\
\hline Crystal System & \multicolumn{2}{|c|}{ Cubic } & \multicolumn{2}{|c|}{ Tetragonal } & \multicolumn{2}{|c|}{ Cubic } & \multicolumn{2}{|c|}{ Tetragonal } \\
\hline Space Group & \multicolumn{2}{|c|}{$P m-3 m$} & \multicolumn{2}{|c|}{$\mathrm{P} 4 \mathrm{~mm}$} & \multicolumn{2}{|c|}{$\mathrm{Pm}-3 \mathrm{~m}$} & \multicolumn{2}{|c|}{$\mathrm{P} 4 \mathrm{~mm}$} \\
\hline lattice Parameters & & SDs & & SDs & & SDs & & SDs \\
\hline $\mathrm{a}(\AA)$ & 4.009733 & 0.000098 & 3.995145 & 0.000079 & 4.009125 & 0.000259 & 3.994512 & 0.000045 \\
\hline $\mathrm{b}(\AA)$ & 4.009733 & 0.000098 & 3.995145 & 0.000079 & 4.009125 & 0.000259 & 3.994512 & 0.000045 \\
\hline$c(\AA)$ & 4.009733 & 0.000098 & 4.031496 & 0.000108 & 4.009125 & 0.000259 & 4.033964 & 0.000056 \\
\hline Cell Volume $\left(\AA^{3}\right)$ & 64.468 & 0.005 & 64.347 & 0.002 & 64.439 & 0.012 & 64.366 & 0.002 \\
\hline Weight Fraction & 0.37539 & 0.0069 & 0.62461 & 0.0042 & 0.24147 & 0.0041 & 0.75853 & 0.0013 \\
\hline
\end{tabular}

In addition to the phase composition, the discrepancies in the microstructures of BTO and BTO-A were studied by transmission electron microscopy. BTO was found to consist of crystalline particles of micrometer size. Most of the particles observed exhibited the presence of $\{1-11\}$ twin domains. Formation of such twins is attributed to changing from the cornersharing $\mathrm{TiO}_{6}$ octahedral stacking to local $\mathrm{Ti}_{2} \mathrm{O}_{9}$ face-sharing octahedral sequence. $\{1-11\}$ twin domains have been described in detail in several microstructural studies of BTO[26,27], in which the oxygen content has been identified as one of the main factors in the $\{111\}$ twin formation. In BTO-A, the grains appear to contain much larger domains. Very weak diffuse streaks were found in SAED patterns taken along the [110] direction, indicating the presence of disorder in the crystals; no clear evidence of $\{1-11\}$ twin domains present in the annealed samples was found. Selected area electron diffraction (SAED) patterns cannot distinguish unambiguously between tetragonal and cubic crystals since the error in determining the unit cell parameters from the SAED patterns is of the same order as the difference between the $a$ and $c$ parameters of the tetragonal lattice. However, comparing the XRD and TEM results suggests that the process of annealing increases the size of the crystallographic domains, 
reducing the instance of twinning, thus reducing the strain in the crystal and allowing a larger amount of the more stable tetragonal, ferroelectric phase to form. Analysis of the XRD and TEM indicates that the process of strain reduction during annealing involves the breaking up of the most strained cubic and tetragonal grains, to produce small tetragonal grains leading to reduced average tetragonal grain size.

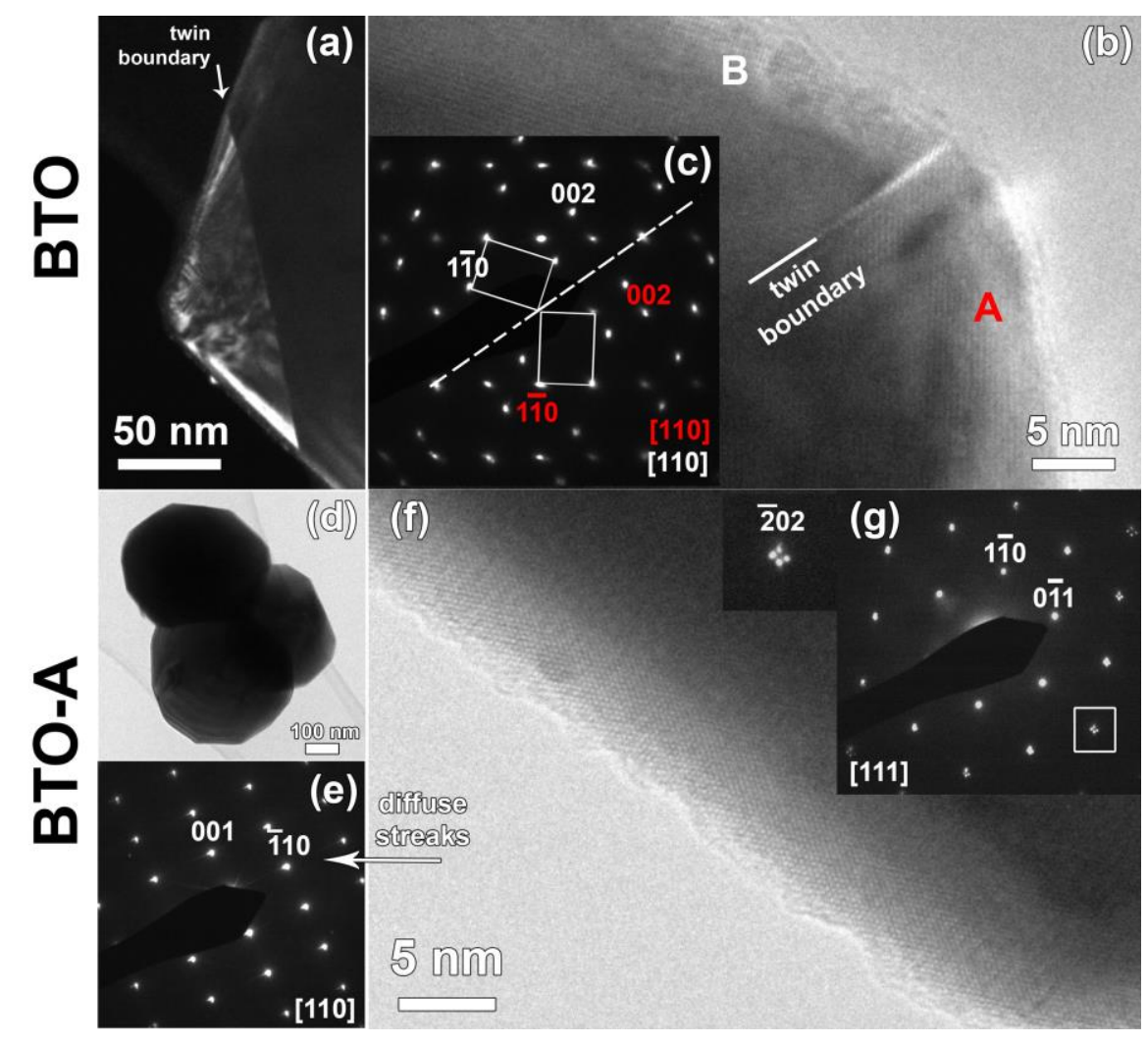

Figure 3. (a) Dark-field image of the BTO grain with twin boundary, (b) high-resolution TEM (HRTEM) image of twin boundary in BTO, and corresponding SAED pattern (c); (d) overview image of the BTO-A grains, (e) SAED pattern taken along the [110] direction with weak lines of diffuse scattering present, (f) HRTEM image and $(\mathrm{g})$ corresponding SAED pattern.

The morphologies of the obtained heterostructured photocatalysts were investigated under SEM and TEM, as shown in Fig. 4. The particle size increases after annealing as can be seen in in Fig. 4(a) and (b) and no obvious secondary phases are observed in either samples. However, the EDX spectrum of $\mathrm{BTO} / \alpha-\mathrm{Fe}_{2} \mathrm{O}_{3}$ (Fig. 4(e)) and $\mathrm{BTO}-\mathrm{A} / \alpha-\mathrm{Fe}_{2} \mathrm{O}_{3}$ (Fig. S2) 
demonstrates the existence of Fe in the sample. The TEM micrographs (Fig. 4(c) and (d)) further show the heterostructure between a thin layer of second species and BTO or BTO-A. The thickness of this layer varies on the surface, from 10 to $25 \mathrm{~nm}$. No discrepancies of this layer between $\mathrm{BTO} / \alpha-\mathrm{Fe}_{2} \mathrm{O}_{3}$ and $\mathrm{BTO}-\mathrm{A} / \alpha-\mathrm{Fe}_{2} \mathrm{O}_{3}$ are observed.
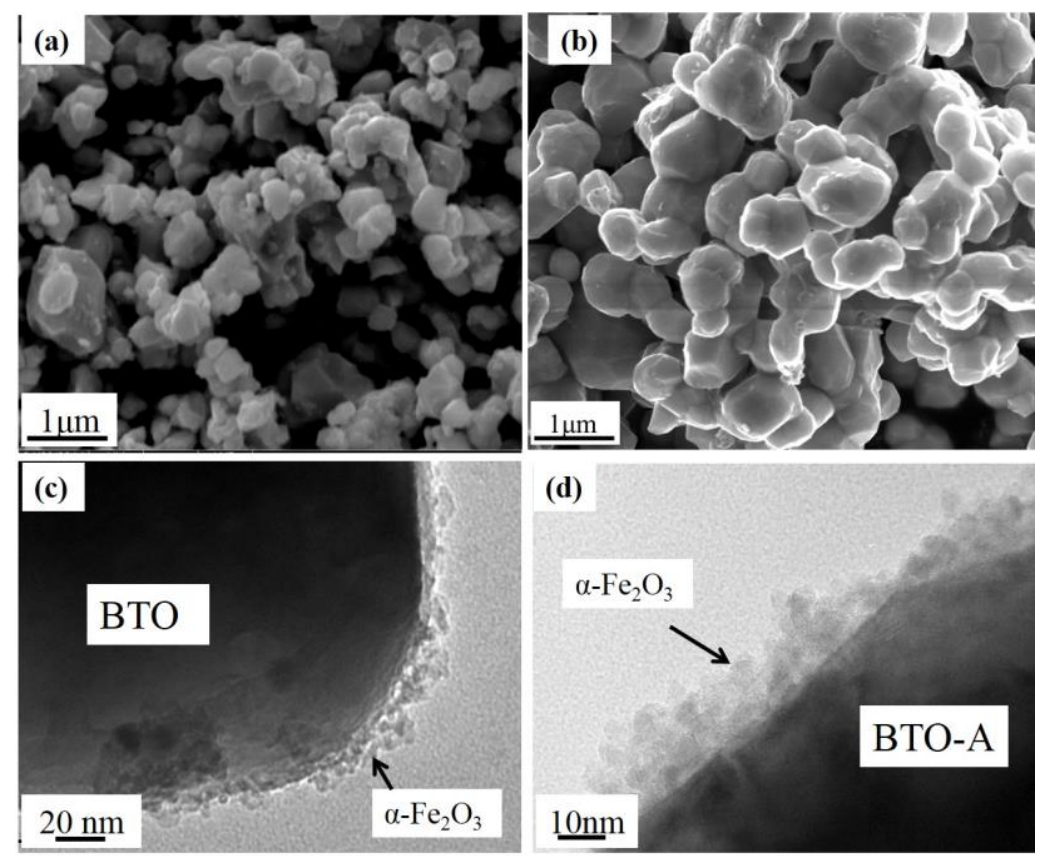

(d)

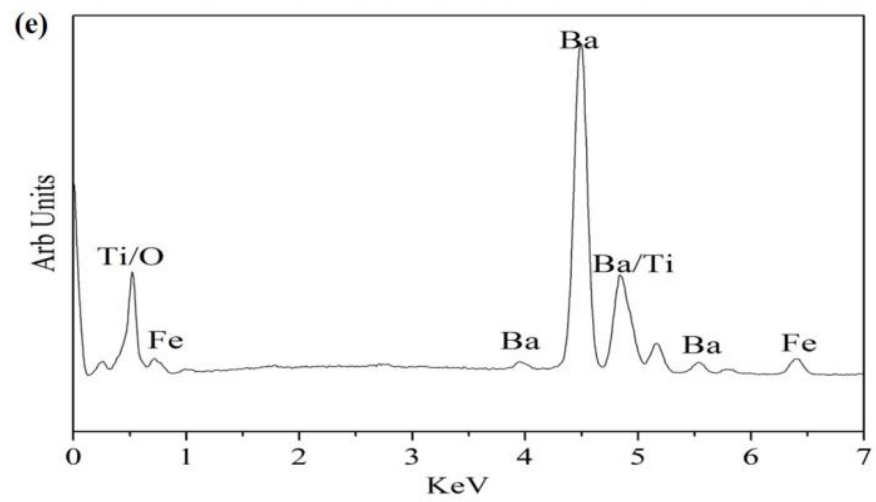

Figure 4. SEM micrographs of (a) BTO/ $\alpha-\mathrm{Fe}_{2} \mathrm{O}_{3}$, (b) BTO-A $/ \alpha-\mathrm{Fe}_{2} \mathrm{O}_{3}$ and TEM micrographs (c) $\mathrm{BTO} / \alpha-\mathrm{Fe}_{2} \mathrm{O}_{3}$, (d)BTO-A $/ \alpha-\mathrm{Fe}_{2} \mathrm{O}_{3}$, and (e) EDX spectrum of $\mathrm{BTO} / \alpha-\mathrm{Fe}_{2} \mathrm{O}_{3}$. A thin layer of $\mathrm{Fe}$ species formed on the surface of BTO and BTO-A.

To further demonstrate the successful synthesis of heterogeneous photocatalysts, the surface composition and chemical state of samples was analysed by XPS (Figure 5). The spectra of both samples show signal peaks from Fe element in addition to the peaks from elements $\mathrm{Ba}$, Ti and O. As presented in Fig. 5 (b), the spectrum of Fe 2p is made up of two characteristic 
peaks, $\mathrm{Fe} 2 \mathrm{p}_{1 / 2}$ at $724.2 \mathrm{eV}$ and $2 \mathrm{p}_{3 / 2}$ at $710.7 \mathrm{eV}$ respectively. These peak positions are in agreement with the reported XPS peak locations of $\alpha-\mathrm{Fe}_{2} \mathrm{O}_{3}$ within the common variations between 724.4 and $724.7 \mathrm{eV}$ for $\mathrm{Fe} 2 \mathrm{p}_{2 / 1}$, and between $710.6 \mathrm{eV}$ to $711.2 \mathrm{eV}$ for $\mathrm{Fe}$ $2 \mathrm{p}_{3 / 2}[22,28,29]$. Apart from the peak position, a characteristic satellite which is located between the two main peaks also suggests the existence of $\alpha-\mathrm{Fe}_{2} \mathrm{O}_{3}$ on the surface[22,28,29]. The XPS analysis demonstrates that the Fe species observed with TEM/EDX is $\alpha-\mathrm{Fe}_{2} \mathrm{O}_{3}$.
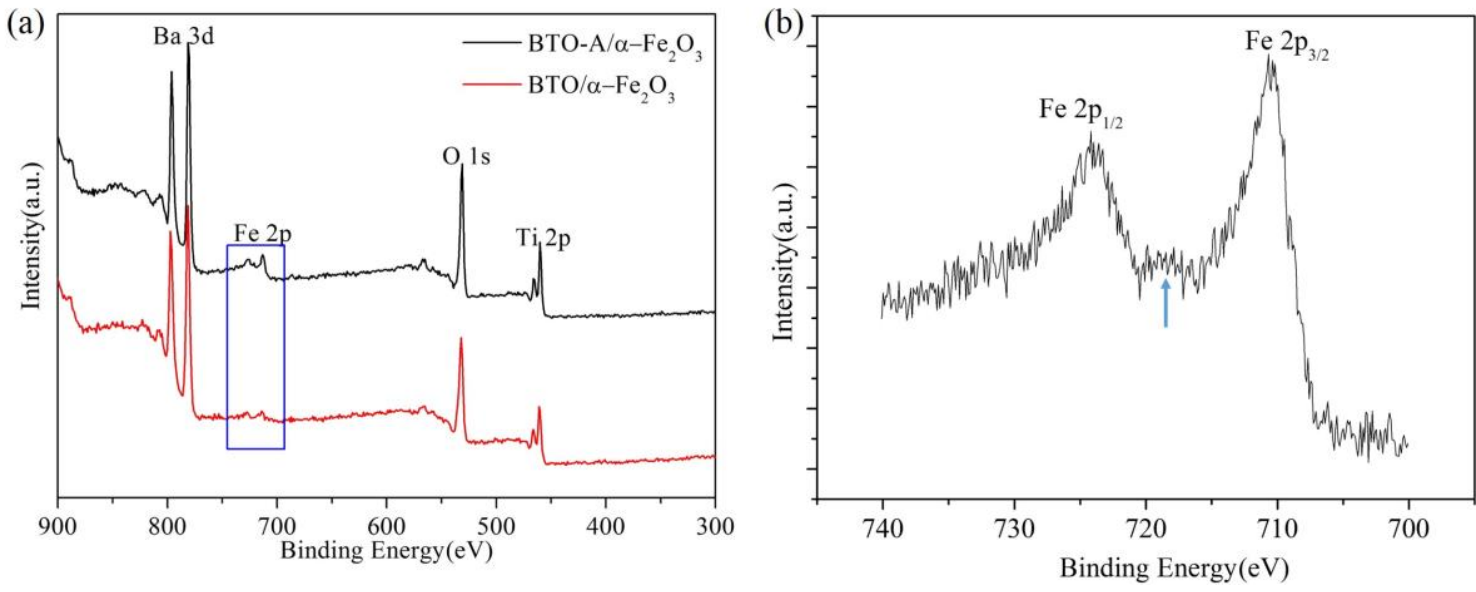

Figure 5. XPS spectra of (a) BTO/ $\alpha-\mathrm{Fe}_{2} \mathrm{O}_{3}$ and $\mathrm{BTO}-\mathrm{A} / \alpha-\mathrm{Fe}_{2} \mathrm{O}_{3}$ and (b) $\mathrm{Fe} 2 \mathrm{p}$. The existence of characteristic peaks of $\mathrm{Fe}$ in $\alpha-\mathrm{Fe}_{2} \mathrm{O}_{3}$ demonstrate the material formed on the surface is $\alpha-\mathrm{Fe}_{2} \mathrm{O}_{3}$.

The optical properties of BTO/ $\alpha-\mathrm{Fe}_{2} \mathrm{O}_{3}$ and $\mathrm{BTO}-\mathrm{A} / \alpha-\mathrm{Fe}_{2} \mathrm{O}_{3}$ with bare BTO and BTO-A were investigated as well, as shown in Figure 6. As expected, the absorption intensity of both $\mathrm{BTO} / \alpha-\mathrm{Fe}_{2} \mathrm{O}_{3}$ and $\mathrm{BTO}-\mathrm{A} / \alpha-\mathrm{Fe}_{2} \mathrm{O}_{3}$ in the visible-light range increase compared with bare BTO and BTO-A due to the surface loading of $\mathrm{Fe}_{2} \mathrm{O}_{3}$. As known, $\alpha-\mathrm{Fe}_{2} \mathrm{O}_{3}$ has a narrow band gap and can absorb most of the visible light[23]. In addition, comparing the absorption spectra between $\mathrm{BTO} / \alpha-\mathrm{Fe}_{2} \mathrm{O}_{3}$ and $\mathrm{BTO}-\mathrm{A} / \alpha-\mathrm{Fe}_{2} \mathrm{O}_{3}$, only a minor discrepancy is seen, indicating the same loading amount of $\alpha-\mathrm{Fe}_{2} \mathrm{O}_{3}$ and similar absorption properties. 


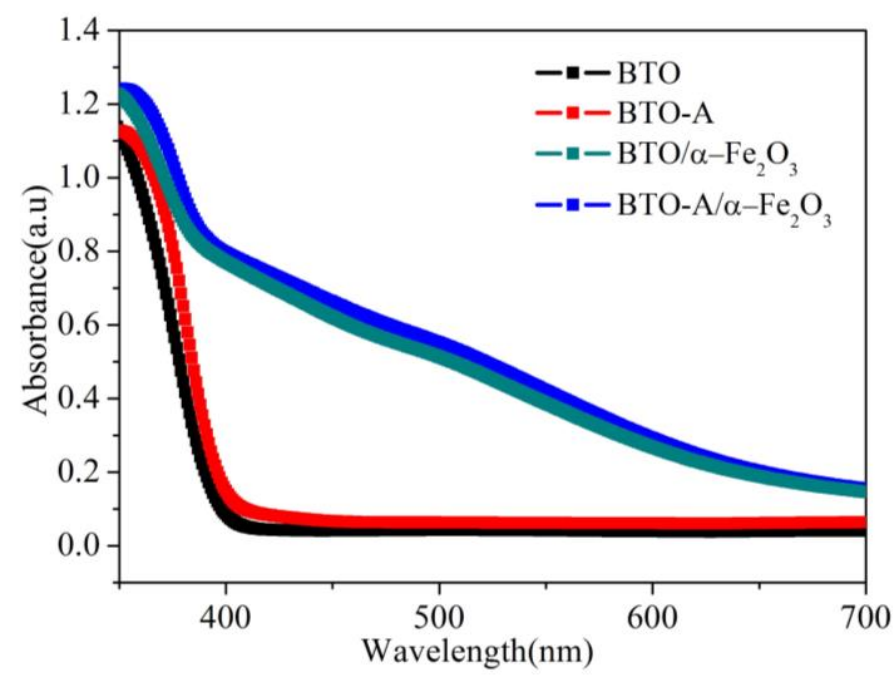

Figure 6. Diffuse reflectance spectra of BTO/ $\alpha-\mathrm{Fe}_{2} \mathrm{O}_{3}, \mathrm{BTO}-\mathrm{A} / \alpha-\mathrm{Fe}_{2} \mathrm{O}_{3}, \mathrm{BTO}$ and BTO-A. The absorption in visible-light range increase due to the surface loading of $\alpha-\mathrm{Fe}_{2} \mathrm{O}_{3}$.

Combining SEM/TEM/EDX and XPS, it can be concluded that heterostructured photocatalysts were produced successfully, and there is no significant difference in the surface composition or chemical state between these two photocatalysts.

The photocatalytic activity of photocatalysts was evaluated by decolourisation of Rhodamine B under solar light (Fig. 7). For reference pure $\alpha-\mathrm{Fe}_{2} \mathrm{O}_{3}$ was included as well. The adsorption of $\mathrm{RhB}$ on $\alpha-\mathrm{Fe}_{2} \mathrm{O}_{3}$ is highest due to its very large surface area (over $70 \mathrm{~m}^{2} / \mathrm{g}$ ) compared with the other four samples $\left(1-2 \mathrm{~m}^{2} / \mathrm{g}\right.$, see Table 2). Despite a strong adsorption, pure $\alpha-\mathrm{Fe}_{2} \mathrm{O}_{3}$ shows the slowest photodegradation rate in two hours, indicating its poor role as photocatalysts. After $\mathrm{BaTiO}_{3}$ coupling with $\alpha-\mathrm{Fe}_{2} \mathrm{O}_{3}$, both heterostructured photocatalysts show improved activity compared with bare BTO or BTO-A, and $\alpha-\mathrm{Fe}_{2} \mathrm{O}_{3}$ as well. However, the annealed photocatalysts, which contain more ferroelectric phase, show improved activity compared to unannealed samples. Under the identical experiment conditions, BTO-A/ $\alpha-$ $\mathrm{Fe}_{2} \mathrm{O}_{3}$ also shows improved decolourisation performance with respect to $\mathrm{BTO} / \alpha-\mathrm{Fe}_{2} \mathrm{O}_{3}$ despite a smaller surface area (Fig. 7 and Table 2). The half-time of photodecolourisation decreases from 87 min for $\mathrm{BTO} / \alpha-\mathrm{Fe}_{2} \mathrm{O}_{3}$ to 55 min for $\mathrm{BTO}-\mathrm{A} / \alpha-\mathrm{Fe}_{2} \mathrm{O}_{3}$. 

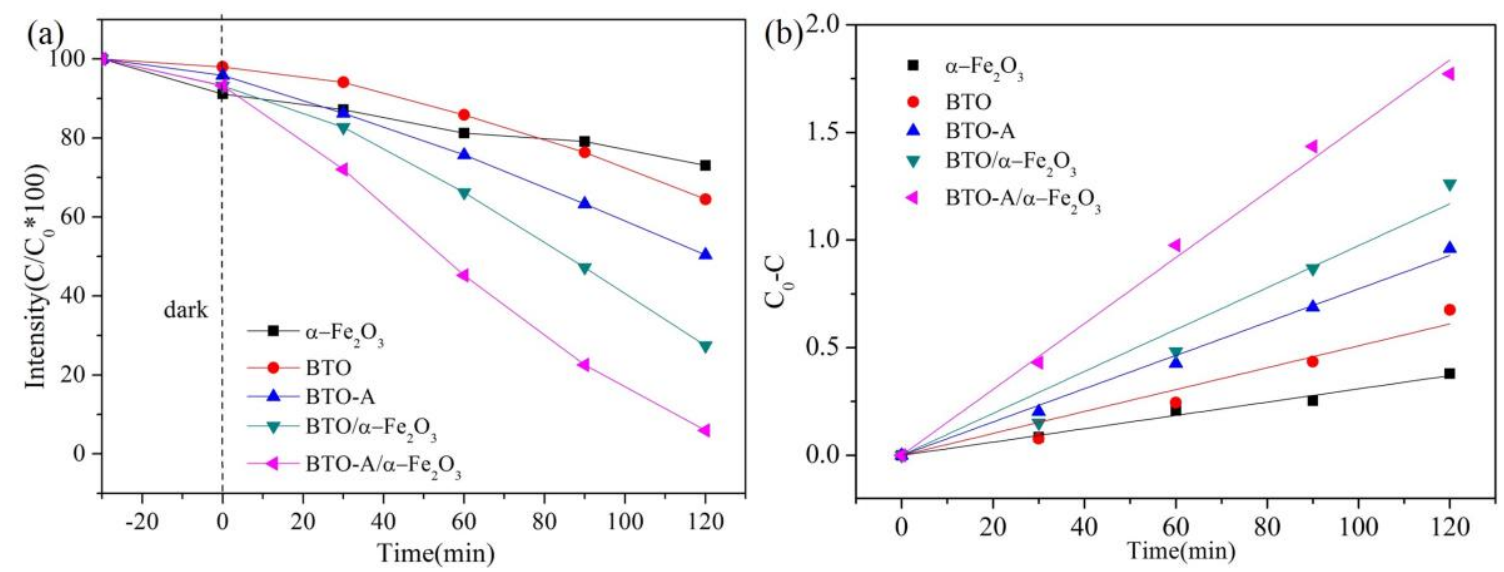

Figure 7. (a) Photodecolourisation profiles with different photocatalysts, (b) linear fitting profiles of $C_{0}-C$ versus. $t$. BTO-A $/ \alpha-\mathrm{Fe}_{2} \mathrm{O}_{3}$ shows the highest photocatalytic activity. Both $\mathrm{BTO} / \alpha-\mathrm{Fe}_{2} \mathrm{O}_{3}$ and BTO-A $/ \alpha-\mathrm{Fe}_{2} \mathrm{O}_{3}$ show faster photodecolourisation rate compared to bare BTO and BTO-A respectively.

Table 2 Surface areas, calculated $\mathrm{t}_{1 / 2}$ and $\mathrm{k}_{\mathrm{obs}}$ of different photocatalysts

\begin{tabular}{|c|c|c|c|c|c|}
\hline Photocatalysts & $\alpha-\mathrm{Fe}_{2} \mathrm{O}_{3}$ & BTO & ВTO-A & $\mathrm{BTO} / \alpha-\mathrm{Fe}_{2} \mathrm{O}_{3}$ & $\begin{array}{c}\text { BTO-A/ } \alpha- \\
\mathrm{Fe}_{2} \mathrm{O}_{3}\end{array}$ \\
\hline $\begin{array}{l}\text { BET Surface } \\
\text { Area }\left(\mathrm{m}^{2} / \mathrm{g}\right)\end{array}$ & 72.17 & 2.06 & 0.86 & 2.74 & 0.66 \\
\hline $\mathbf{t}_{1 / 2}(\min )$ & 252 & 193 & 131 & 87 & 55 \\
\hline $\mathbf{k}_{\text {obs }}$ & 0.0038 & 0.00509 & 0.00773 & 0.00973 & 0.0153 \\
\hline $\mathbf{R}^{2}$ & 0.994 & 0.976 & 0.997 & 0.981 & 0.998 \\
\hline
\end{tabular}

As discussed in our previous work[6], the higher level of tetragonal material in the BTO-A sample and corresponding $\mathrm{Fe}_{2} \mathrm{O}_{3}$-coated sample would be expected to increase the ferroelectric phase content and have an predominant impact on the catalytic activity, which will be discussed below in detail.

The advantage of ferroelectric photocatalysts can be explained by the different band configuration in the heterojunction structure, as shown in Fig. 8. The specific conduction band positions of $\mathrm{BaTiO}_{3}$ and $\alpha-\mathrm{Fe}_{2} \mathrm{O}_{3}$ were determined based on the empirical formula, $E_{C B}=X-E_{\mathrm{e}}-0.5 E_{g}[30] . X$ is the electronegativity of the semiconductor, $E_{\mathrm{e}}$ is the energy of free electrons on the hydrogen scale (about $4.5 \mathrm{eV}$ ), and $E_{\mathrm{g}}$ is the band gap energy of the semiconductor. The band gap energy of $\mathrm{BaTiO}_{3}$ and $\alpha-\mathrm{Fe}_{2} \mathrm{O}_{3}$ were assumed to be $3.2 \mathrm{eV}$ and 
$2.2 \mathrm{eV}[22,31]$. Then the conduction band edge of $\mathrm{BaTiO}_{3}$ and $\alpha-\mathrm{Fe}_{2} \mathrm{O}_{3}$ were calculated to be at $-0.86 \mathrm{eV}$ and $0.29 \mathrm{eV}$ versus NHE. Accordingly the valence band positions were at $2.34 \mathrm{eV}$ and $2.49 \mathrm{eV}$ respectively. As for the Fermi level position of n-type $\mathrm{BaTiO}_{3}$, it was assumed to be $0.1 \mathrm{eV}$ lower than the conduction band edge[31,32] A $5.4 \mathrm{eV}$ work function of $\alpha-\mathrm{Fe}_{2} \mathrm{O}_{3}$ [33] was used to situate its Fermi level relative to the vacuum level, i.e. $0.61 \mathrm{eV}$ below its conduction band edge.

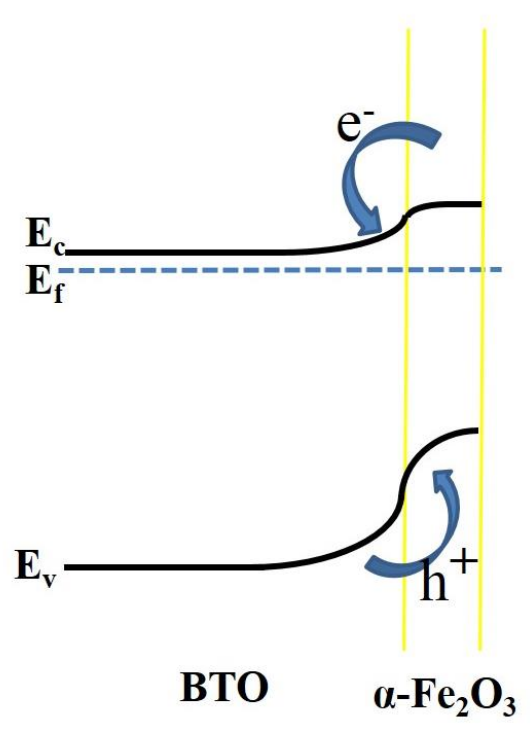

(a)

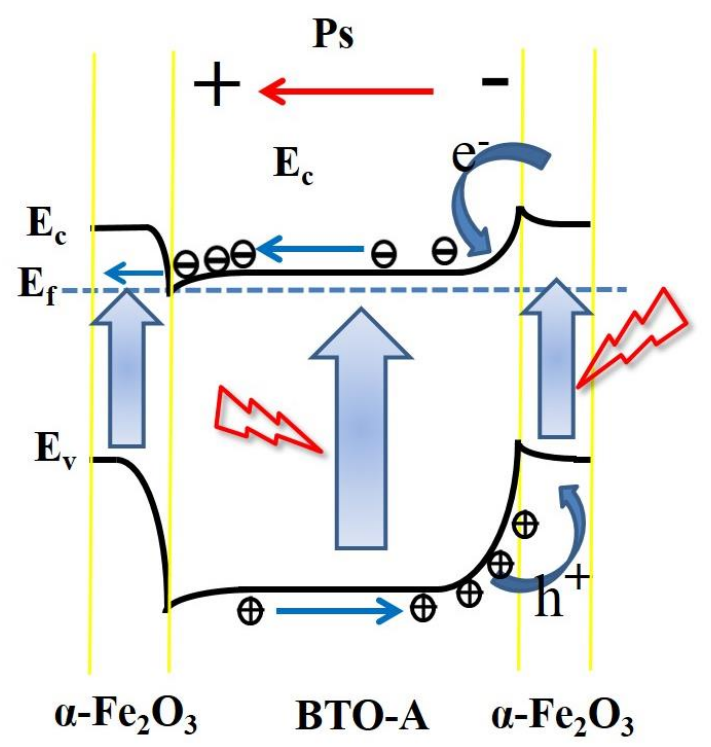

(b)

Figure 8. Schematic showing the band configuration of (a) BTO/ $\alpha-\mathrm{Fe}_{2} \mathrm{O}_{3}$ and (b) $\mathrm{BTO}-\mathrm{A} / \alpha-\mathrm{Fe}_{2} \mathrm{O}_{3}$.

When two semiconductors are contacted with each other, the electrons will flow from the material with a higher Fermi level to that with a lower Fermi level to achieve Fermi level alignment[34]. This will result in band bending and space charge layer formation, which is similar to a typical p-n junction. After considering the band structures of BTO and $\alpha-\mathrm{Fe}_{2} \mathrm{O}_{3}$, the mechanism shown in Fig. 8(a) was put forward in the case of non-ferroelectric BTO. The improved charge carrier transport due to the electric field in space charge layer accounted for the enhanced photodecolourisation rate of $\mathrm{BTO} / \alpha-\mathrm{Fe}_{2} \mathrm{O}_{3}$. 
With respect to ferroelectric BTO-A system, the band bending due to ferroelectricity should be considered apart from band bending arising from heterojunction. The band bending contributed from the polarisation of $\mathrm{BaTiO}_{3}$ will counteract or superimpose the band bending due to the heterojunction, depending on the polarisation directions[35,36]. At the negative charged surface of $\mathrm{BaTiO}_{3}(\mathrm{C}-)$ where the bands bend upward, electrons and holes can be efficiently separated due to the difference electrochemical potential of conduction and valence band across the interface. As for the positive charged region $(\mathrm{C}+)$ where the band bends downward, electrons accumulate in the interface, and it may be possible for electrons to tunnel through the layer of $\mathrm{Fe}_{2} \mathrm{O}_{3}$ considering its low thickness $(<10 \mathrm{~nm})$ or the electrons can be directly available in the regions where not covered by $\mathrm{Fe}_{2} \mathrm{O}_{3}$ (Fig. 4, TEM micrographs).

In addition, it should be mentioned that the charge carrier behaviour of $\alpha-\mathrm{Fe}_{2} \mathrm{O}_{3}$ coupled on ferroelectric BTO-A can be influenced by the polarisation of BTO-A. It has been recently reported [37] that in a coupled semiconductor-ferroelectric $\mathrm{Ag}_{2} \mathrm{O}-\mathrm{BaTiO}_{3}$ system, the polarisation field in $\mathrm{BaTiO}_{3}$ can act as driving force to attract or repel charge carriers in the attached $\mathrm{Ag}_{2} \mathrm{O}$. This similar phenomenon was observed in the hybrid polymer/ZnO photovoltaic devices, and a 3-fold increase in charge carrier lifetime was obtained under applied acoustic vibration[38]. The credit was given to the piezoelectric polarisation of $\mathrm{ZnO}$ nanorods, reducing recombination and extending carrier lifetime. Therefore, a similar statement was proposed in our system. In positive polarisation, electrons will move towards the interface while holes accumulated near the interface in the case of negative polarisations. Then the charge carrier lifetime of $\alpha-\mathrm{Fe}_{2} \mathrm{O}_{3}$ will be extended due to this enhanced carrier separation, which can also contribute to the enhancement in photocatalytic activity. 


\section{Conclusions}

The heterogeneous photocatalysts $\mathrm{BTO} / \alpha-\mathrm{Fe}_{2} \mathrm{O}_{3}$ and $\mathrm{BTO}-\mathrm{A} / \alpha-\mathrm{Fe}_{2} \mathrm{O}_{3}$ were successfully synthesised as demonstrated by XRD, SEM/TEM/EDX and XPS analysis, showing that BTO-A had a higher tetragonal, and therefore ferroelectric phase content compared to BTO. Their photocatalytic activity were compared through photodecolourisation of Rhodamine B under artificial sunlight. It was found under the identical experimental conditions, BTO-A/ $\alpha-$ $\mathrm{Fe}_{2} \mathrm{O}_{3}$ showed higher photodecolourisation rate compared to $\mathrm{BTO} / \alpha-\mathrm{Fe}_{2} \mathrm{O}_{3}$. This was attributed predominantly to the efficient charge carrier separation at the interface and improved lifetime of charge carriers in $\alpha-\mathrm{Fe}_{2} \mathrm{O}_{3}$ due to the increased ferroelectric dipole in BTO-A.

\section{References}

[1] H.G. Kim, P.H. Borse, J.S. Jang, E.D. Jeong, O.-S. Jung, Y.J. Suh, et al., Fabrication of $\mathrm{CaFe} 2 \mathrm{O} 4 / \mathrm{MgFe} 2 \mathrm{O} 4$ bulk heterojunction for enhanced visible light photocatalysis, Chem. Commun. (2009) 5889-5891. doi:10.1039/B911805E.

[2] D. Wang, Z. Zou, J. Ye, Photocatalytic Water Splitting with the Cr-Doped Ba2In2O5/In2O3 Composite Oxide Semiconductors, Chem. Mater. 17 (2005) 32553261. doi:10.1021/cm0477117.

[3] D.R. Baker, P. V Kamat, Photosensitization of TiO2 Nanostructures with CdS Quantum Dots: Particulate versus Tubular Support Architectures, Adv. Funct. Mater. 19 (2009) 805-811. doi:10.1002/adfm.200801173.

[4] C. Wang, R.L. Thompson, P. Ohodnicki, J. Baltrus, C. Matranga, Size-dependent photocatalytic reduction of $\mathrm{CO} 2$ with $\mathrm{PbS}$ quantum dot sensitized $\mathrm{TiO} 2$ heterostructured photocatalysts, J. Mater. Chem. 21 (2011) 13452. doi:10.1039/c1jm12367j.

[5] L. Li, P.A. Salvador, G.S. Rohrer, Photocatalysts with internal electric fields, Nanoscale. (2013). doi:10.1039/C3NR03998F.

[6] Y. Cui, J. Briscoe, S. Dunn, Effect of Ferroelectricity on Solar-Light-Driven Photocatalytic Activity of BaTiO3 - Influence on the Carrier Separation and Stern Layer Formation, Chem. Mater. 25 (2013) 4215-4223. doi:10.1021/cm402092f.

[7] S.S. Roy, H. Gleeson, C.P. Shaw, R.W. Whatmore, Z. Huang, Q. Zhang, et al., Growth and characterisation of lead zirconate titanate (30/70) on indium tin oxide coated glass 
for oxide ferroelectric-liquid crystal display application, Integr. Ferroelectr. 29 (2000) 189-213.

[8] L. Loh, J. Briscoe, S. Dunn, Enhanced performance with bismuth ferrite perovskite in ZnO nanorod solid state solar cells., Nanoscale. (2014) 7072-7078. doi:10.1039/c4nr00911h.

[9] J. Briscoe, M. Stewart, M. Vopson, M. Cain, P.M. Weaver, S. Dunn, Nanostructured p-n Junctions for Kinetic-to-Electrical Energy Conversion, Adv. Energy Mater. 2 (2012) 1261-1268. doi:10.1002/aenm.201200205.

[10] J. Briscoe, N. Jalali, P. Woolliams, M. Stewart, P.M. Weaver, M. Cain, et al., Measurement techniques for piezoelectric nanogenerators, Energy Environ. Sci. 6 (2013) 3035. doi:10.1039/c3ee41889h.

[11] S. Dunn, Strain behavior of thin film PbZr0. 3Ti0. $7 \mathrm{O} 3$ (30/70) examined through piezoforce microscopy, J. Appl. Phys. 94 (2003) 5964-5968.

[12] F. Boxberg, N. Sondergaard, H.Q. Xu, Photovoltaics with Piezoelectric Core-Shell Nanowires, Nano Lett. 10 (2010) 1108-1112. doi:10.1021/n19040934.

[13] J.L. Giocondi, G.S. Rohrer, Spatially Selective Photochemical Reduction of Silver on the Surface of Ferroelectric Barium Titanate, Chem. Mater. 13 (2001) 241-242. doi:10.1021/cm000890h.

[14] D. Tiwari, S. Dunn, Photochemistry on a polarisable semi-conductor: what do we understand today?, J. Mater. Sci. 44 (2009) 5063-5079. doi:10.1007/s10853-009$3472-1$

[15] Y. Inoue, M. Okamura, K. Sato, A thin-film semiconducting titanium dioxide combined with ferroelectrics for photoassisted water decomposition, J. Phys. Chem. 89 (1985) 5184-5187. doi:10.1021/j100270a013.

[16] N. V Burbure, P.A. Salvador, G.S. Rohrer, Photochemical Reactivity of Titania Films on BaTiO3 Substrates: Origin of Spatial Selectivity, Chem. Mater. 22 (2010) 58235830. doi:10.1021/cm1018025.

[17] N. V. Burbure, P.A. Salvador, G.S. Rohrer, Photochemical Reactivity of Titania Films on BaTiO 3 Substrates: Influence of Titania Phase and Orientation, Chem. Mater. 22 (2010) 5831-5837. doi:10.1021/cm1018019.

[18] M. Stock, S. Dunn, LiNbO3--a new material for artificial photosynthesis., IEEE Trans. Ultrason. Ferroelectr. Freq. Control. 58 (2011) 1988-93. doi:10.1109/TUFFC.2011.2042.

[19] S.M. Hatch, J. Briscoe, S. Dunn, A self-powered ZnO-nanorod/CuSCN UV photodetector exhibiting rapid response., Adv. Mater. 25 (2013) 867-71. doi:10.1002/adma.201204488.

[20] R. Su, Y. Shen, L. Li, D. Zhang, G. Yang, C. Gao, et al., Silver-Modified Nanosized Ferroelectrics as a Novel Photocatalyst, Small. 11 (2015) 202-207. doi:10.1002/smll.201401437.

[21] A. Di Paola, E. García-López, G. Marcì, L. Palmisano, A survey of photocatalytic materials for environmental remediation, J. Hazard. Mater. 211-212 (2012) 3-29. doi:http://dx.doi.org/10.1016/j.jhazmat.2011.11.050.

[22] G. Wang, Y. Ling, D.A. Wheeler, K.E.N. George, K. Horsley, C. Heske, et al., Facile Synthesis of Highly Photoactive $\alpha$-Fe2O3-Based Films for Water Oxidation, Nano Lett. 11 (2011) 3503-3509. doi:10.1021/nl202316j. 
[23] L. Peng, T. Xie, Y. Lu, H. Fan, D. Wang, Synthesis, photoelectric properties and photocatalytic activity of the $\mathrm{Fe} 2 \mathrm{O} 3 / \mathrm{TiO} 2$ heterogeneous photocatalysts, Phys. Chem. Chem. Phys. 12 (2010) 8033-8041. doi:10.1039/C002460K.

[24] W. Zhou, H. Fu, K. Pan, C. Tian, Y. Qu, P. Lu, et al., Mesoporous TiO2/ $\alpha-F e 2 O 3:$ Bifunctional Composites for Effective Elimination of Arsenite Contamination through Simultaneous Photocatalytic Oxidation and Adsorption, J. Phys. Chem. C. 112 (2008) 19584-19589. doi:10.1021/jp806594m.

[25] A.C.L. R. Von Dreele, General Structure Analysis System (GSAS), Los Alamos National Laboratory Report LAUR86-784, 2004.

[26] C.L. Jia, K. Urban, Atomic-Resolution Measurement of Oxygen Concentration in Oxide Materials, Science (80-. ). 303 (2004) 2001-2004.

http://science.sciencemag.org/content/303/5666/2001.abstract.

[27] V. Kraševec, M. Drofenik, D. Kolar, Genesis of the (111) Twin in Barium Titanate, J. Am. Ceram. Soc. 73 (1990) 856-860. doi:10.1111/j.1151-2916.1990.tb05125.x.

[28] Y. Guo, G. Zhang, J. Liu, Y. Zhang, Hierarchically structured [small alpha]$\mathrm{Fe} 2 \mathrm{O} 3 / \mathrm{Bi} 2 \mathrm{WO} 6$ composite for photocatalytic degradation of organic contaminants under visible light irradiation, RSC Adv. 3 (2013) 2963-2970. doi:10.1039/C2RA22741J.

[29] T. Yamashita, P. Hayes, Analysis of XPS spectra of Fe2+ and Fe3+ ions in oxide materials, Appl. Surf. Sci. 254 (2008) 2441-2449. doi:http://dx.doi.org/10.1016/j.apsusc.2007.09.063.

[30] M.A. Butler, D.S. Ginley, Prediction of Flatband Potentials at SemiconductorElectrolyte Interfaces from Atomic Electronegativities, J. Electrochem. Soc. 125 (1978) 228-232.

[31] L. Li, G.S. Rohrer, P.A. Salvador, Heterostructured Ceramic Powders for Photocatalytic Hydrogen Production: Nanostructured TiO2 Shells Surrounding Microcrystalline (Ba,Sr)TiO3 Cores, J. Am. Ceram. Soc. 95 (2012) 1414-1420. doi:10.1111/j.1551-2916.2012.05076.x.

[32] L. Li, X. Liu, Y. Zhang, P.A. Salvador, G.S. Rohrer, Heterostructured (Ba,Sr)TiO3/TiO2 core/shell photocatalysts: Influence of processing and structure on hydrogen production, Int. J. Hydrogen Energy. 38 (2013) 6948-6959. doi:http://dx.doi.org/10.1016/j.ijhydene.2013.03.130.

[33] Z. Fan, X. Wen, S. Yang, J.G. Lu, Controlled p- and n-type doping of Fe2O3 nanobelt field effect transistors, Appl. Phys. Lett. 87 (2005) -. doi:http://dx.doi.org/10.1063/1.1977203.

[34] S.J.A. Moniz, S.A. Shevlin, D.J. Martin, Z.-X. Guo, J. Tang, Visible-light driven heterojunction photocatalysts for water splitting - a critical review, Energy Environ. Sci. 8 (2015) 731-759. doi:10.1039/C4EE03271C.

[35] Y. Watanabe, Energy band diagram of ferroelectric heterostructures and its application to the thermodynamic feasibility of ferroelectric FET, Solid State Ionics. 108 (1998) 59-65. doi:http://dx.doi.org/10.1016/S0167-2738(98)00019-8.

[36] Y. Watanabe, Electrical transport through $\mathrm{Pb}(\mathrm{Zr}, \mathrm{Ti}) \mathrm{O} 3 \mathrm{p}-\mathrm{n}$ and $\mathrm{p}$-p heterostructures modulated by bound charges at a ferroelectric surface: Ferroelectric p-n diode, Phys. Rev. B. 59 (1999) 11257-11266. doi:10.1103/PhysRevB.59.11257. 
[37] H. Li, Y. Sang, S. Chang, X. Huang, Y. Zhang, R. Yang, et al., Enhanced Ferroelectric-Nanocrystal-Based Hybrid Photocatalysis by Ultrasonic-Wave-Generated Piezophototronic Effect, Nano Lett. 15 (2015) 2372-2379. doi:10.1021/n1504630j.

[38] S. Shoaee, J. Briscoe, J.R. Durrant, S. Dunn, Acoustic Enhancement of Polymer/ZnO Nanorod Photovoltaic Device Performance, Adv. Mater. 26 (2014) 263-268. doi:10.1002/adma.201303304. 


\section{Supporting Information}
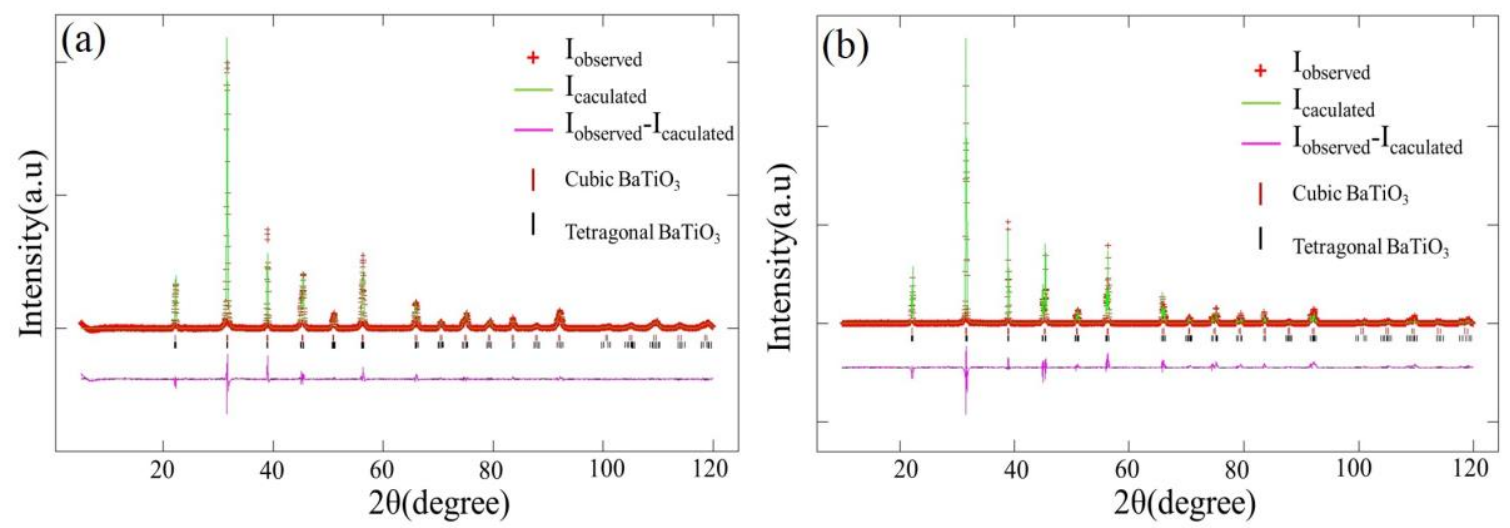

Figure S1. XRD patterns of (a) BTO and (b) BTO-A showing the fit of the Rietveld refinement.

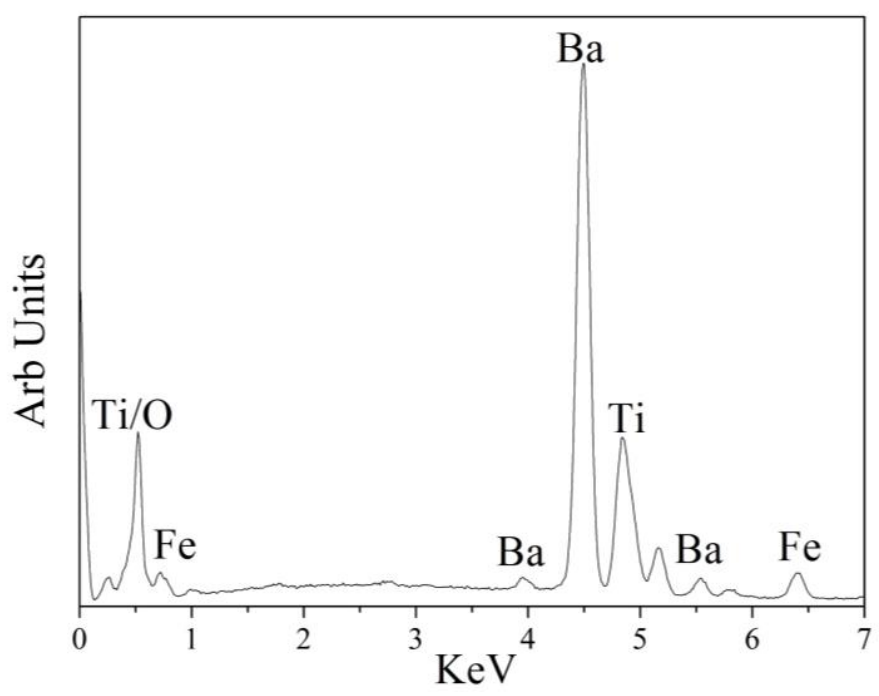

Figure S2. EDX spectrum of BTO-A/ $\alpha-\mathrm{Fe}_{2} \mathrm{O}_{3}$ 